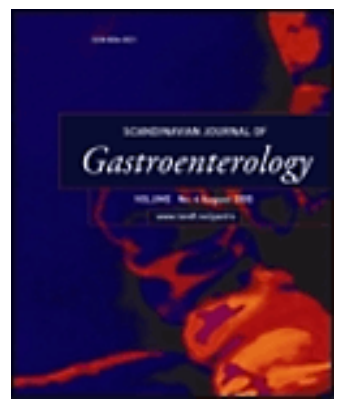

\title{
Narrow band imaging and serology in the assessment of premalignant gastric pathology
}

\begin{tabular}{|c|c|}
\hline Journal: & Scandinavian Journal of Gastroenterology \\
\hline Manuscript ID & SGAS-2018-OR-0762.R1 \\
\hline Manuscript Type: & Original Article \\
\hline $\begin{array}{r}\text { Date Submitted by the } \\
\text { Author: }\end{array}$ & 16-Oct-2018 \\
\hline Complete List of Authors: & $\begin{array}{l}\text { White, Jonathan; Nottingham Digestive Diseases Centre, NIHR } \\
\text { Biomedical Research Centre in Gastrointestinal and Liver Diseases } \\
\text { Sami, Sarmed ; Mayo Clinic Division of Gastroenterology and } \\
\text { Hepatology, Barrett's Esophagus Unit } \\
\text { Reddiar, Dona; Nottingham Digestive Diseases Centre, NIHR Biomedical } \\
\text { Research Centre in Gastrointestinal and Liver Diseases } \\
\text { Mannath, Jayan; University Hospitals Coventry and Warwickshire NHS } \\
\text { Trust, Deaprtment of Gastroenterology } \\
\text { Ortiz Fernández-Sordo, Jacobo; Nottingham Digestive Diseases Centre, } \\
\text { NIHR Biomedical Research Centre in Gastrointestinal and Liver Diseases } \\
\text { Beg, Sabina; Nottingham Digestive Diseases Centre, NIHR Biomedical } \\
\text { Research Centre in Gastrointestinal and Liver Diseases } \\
\text { Scott, Robert; Nottingham Digestive Diseases Centre, NIHR Biomedical } \\
\text { Research Centre in Gastrointestinal and Liver Diseases } \\
\text { Thiagarajan, Prarthana; Nottingham Digestive Diseases Centre, NIHR } \\
\text { Biomedical Research Centre in Gastrointestinal and Liver Diseases } \\
\text { Ahmad, Saqib; Sherwood Forest Hospitals NHS Foundation Trust, } \\
\text { Gastroenterology } \\
\text { Parra-Blanco, Adolfo; Nottingham Digestive Diseases Centre, NIHR } \\
\text { Biomedical Research Centre in Gastrointestinal and Liver Diseases } \\
\text { Kasi, Madhavi; Nottingham Digestive Diseases Centre, NIHR Biomedical } \\
\text { Research Centre in Gastrointestinal and Liver Diseases } \\
\text { Telakis, Emmanouil ; Hellenic Red Cross Hospital, Gastroenterology } \\
\text { Sultan, Alyshah ; Keele University, Research Institute for Primary Care } \\
\text { and Health Sciences } \\
\text { Davis, Jillian; Nottingham University Hospitals NHS Trust, Pathology } \\
\text { Figgins, Adam ; Nottingham University Hospitals NHS Trust, Pathology } \\
\text { Kaye, Philip; Nottingham University Hospitals NHS Trust, Pathology } \\
\text { Robinson, Karen; Nottingham Digestive Diseases Centre, NIHR } \\
\text { Biomedical Research Centre in Gastrointestinal and Liver Diseases } \\
\text { Atherton, John; Nottingham Digestive Diseases Centre, NIHR Biomedical } \\
\text { Research Centre in Gastrointestinal and Liver Diseases } \\
\text { Ragunath, Krish; Nottingham Digestive Diseases Centre, NIHR }\end{array}$ \\
\hline
\end{tabular}


1

2

3

4

5

6

7

8

9

10

11

12

13

14

15

16

17

18

19

20

21

22

23

24

25

26

27

28

29

30

31

32

33

34

35

36

37

38

39

40

41

42

43

44

45

46

47

48

49

50

51

52

53

54

55

56

57

58

59

60
Biomedical Research Centre in Gastrointestinal and Liver Diseases

Keyword: Endoscopy-general, Helicobacter-pylori, Gastritis 


\section{Title Page}

\section{Narrow band imaging and serology in the assessment of premalignant gastric pathology}

Jonathan R White ${ }^{1,2}$, Sarmed S Sami ${ }^{3}$, Dona Reddiar ${ }^{1,2}$, Jayan Mannath ${ }^{4}$, Jacobo Ortiz Fernández-Sordo ${ }^{1,2}$, Sabina Beg ${ }^{1.2}$, Robert Scott ${ }^{1,2}$, Prarthana Thiagarajan ${ }^{1,2}$, Saqib Ahmad ${ }^{5}$, Adolfo Parra-Blanco ${ }^{1,2}$, Madhavi Kasi1 ${ }^{1,2}$, Emmanouil Telakis ${ }^{6}$, Alyshah A Sultan ${ }^{7}$, Jillian Davis ${ }^{8}$, Adam Figgins $^{8}$, Philip Kaye ${ }^{8}$, Karen Robinson ${ }^{1,2}$, John C Atherton ${ }^{1,2}$, Krish Ragunath ${ }^{1,2}$.

${ }^{1}$ NIHR Nottingham Biomedical Research Centre, Nottingham University Hospitals NHS Trust and the University of Nottingham

${ }^{2}$ Nottingham Digestive Diseases Centre, The University of Nottingham

${ }^{3}$ Mayo Clinic Division of Gastroenterology and Hepatology, Rochester, MN, USA

${ }^{4}$ Gastroenterology, University Hospitals Coventry and Warwickshire NHS Trust, Coventry, United Kingdom

${ }^{5}$ Sherwood Forest Hospitals NHS Foundation Trust, Kings Mill Hospital, Sutton in Ashfield, Nottinghamshire, United Kingdom

${ }^{6}$ Department of Gastroenterology, Hellenic Red Cross Hospital, Athens, Greece

${ }^{7}$ Research Institute for Primary Care and Health Sciences, Primary Care Sciences, Keele University, Staffordshire, United Kingdom

${ }^{8}$ Department of Pathology, Nottingham University Hospitals NHS Trust, Queen's Medical Centre Campus, United Kingdom

Corresponding author: Jonathan R White

Corresponding author email: jonathan.white@nottingham.ac.uk

Word count: 3495

Grant support: This work was supported by the National Institute for Health Research Biomedical Research Centre, United Kingdom. 
No authors conflict of interest

\section{Keywords}

Endoscopy, narrow band imaging, white light endoscopy, serology, H. pylori gastritis, gastric atrophy, intestinal metaplasia

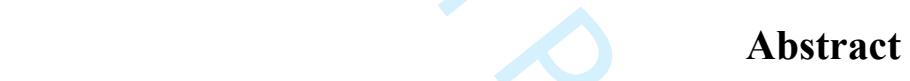

\section{Background}

Patient outcomes in gastric adenocarcinoma are poor due to late diagnosis. Detecting and treating at the premalignant stage has the potential to improve this. H. pylori is also a strong risk factor for this disease.

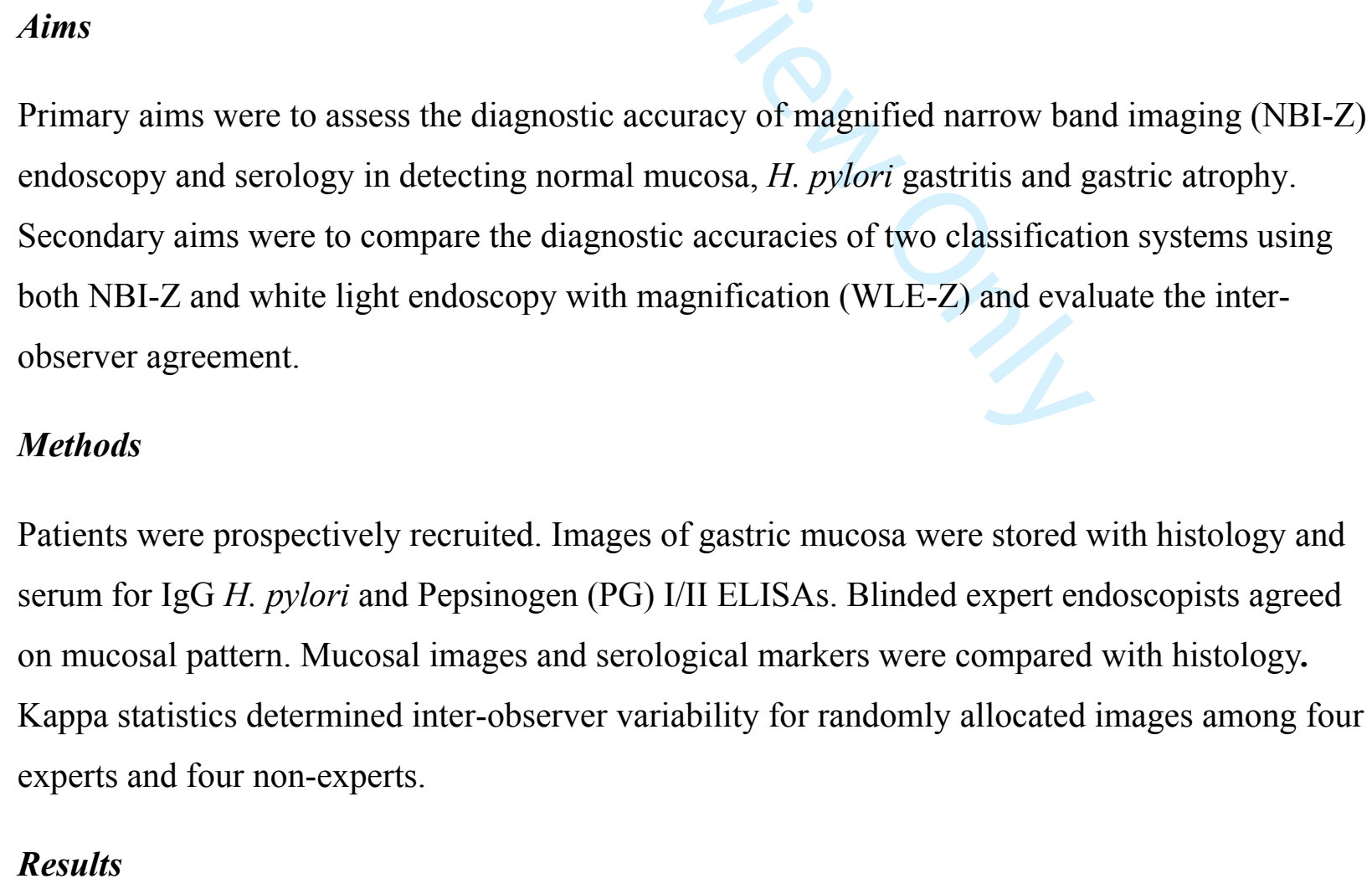

\section{Methods}

Patients were prospectively recruited. Images of gastric mucosa were stored with histology and serum for IgG H. pylori and Pepsinogen (PG) I/II ELISAs. Blinded expert endoscopists agreed on mucosal pattern. Mucosal images and serological markers were compared with histology. Kappa statistics determined inter-observer variability for randomly allocated images among four experts and four non-experts.

\section{Results}


116 patients were prospectively recruited. Diagnostic accuracy of NBI-Z for determining normal gastric mucosa was $0.87(95 \% \mathrm{CI}$ 0.82-0.92), H. pylori gastritis $0.65(95 \% \mathrm{CI}$ 0.55-0.75) and gastric atrophy $0.88(95 \% \mathrm{CI} 0.81-0.94)$. NBI-Z was superior to serology at detecting gastric atrophy: NBI-Z gastric atrophy $0.88(95 \%$ CI $0.81-0.94)$ vs PGI/II ratio<3 0.74(95\%CI 0.62-0.85) $\mathrm{p}<0.0001$. Overall NBI-Z was superior to WLE-Z in detecting disease using two validated classifications. Inter-observer agreement was $0.63(95 \% \mathrm{CI} 0.51-0.73)$.

\section{Conclusions}

NBI-Z accurately detects changes in the GI mucosa which currently depend on histology. NBI-Z is useful in the detection of precancerous lesions, potentially improving patient outcomes with early intervention to prevent gastric cancer.

\section{Introduction}

Helicobacter pylori (H. pylori) colonizes the gastric mucosa of approximately $50 \%$ of the world's population, although the prevalence varies between countries the infection rates are higher in developing countries $(1,2)$. H. pylori infects individuals during childhood and typically persists lifelong in the absence of effective eradication therapy (3). In 15\% of individuals infection leads to serious complications such as peptic ulcer disease, distal gastric adenocarcinoma or primary gastric mucosa associated lymphoid tissue (MALT) lymphoma (4). Other conditions associated with $H$. pylori include iron deficiency anemia, gastric atrophy and idiopathic thrombocytopenia purpura $(5,6)$. H. pylori infection has also been suggested to be a significant contributor to the hygiene hypothesis and the development of a healthy immune system $(4,7)$.

Gastric atrophy occurs as a result of a chronic gastric mucosal inflammation, usually due to $H$. pylori infection, leading to loss of specialized glandular cells and replacement with an intestinal type surface and fibrous tissue (8). This may then progress to intestinal metaplasia then dysplasia and finally intestinal type gastric cancer. The development from normal mucosa to gastric cancer is gradual and in a stepwise manner (9). The annual incidence of progression from intestinal metaplasia to gastric cancer varies from $0.1 \%$ to $0.9 \%$ (10). The annual incidence increases to $6 \%$ in dysplasia $(11,12)$. Gastric atrophy is, therefore, considered a pre-cancerous condition and current European guidelines recommend endoscopic surveillance of these high risk patients with 
severe atrophy (13). Unfortunately, at present these premalignant mucosal changes are often disregarded in routine clinical practice or result in variable surveillance frequency (14). Gastric cancer is ranked the fifth most common malignancy worldwide (15) and is the third most common cause of cancer related death (16). In order to reduce this associated mortality, one possibility is to detect premalignant disease using advanced endoscopy techniques. However, due to variety in endoscopic techniques and mucosal classifications the diagnosis is often dependent on histology.

High definition magnified white light endoscopy (WLE-Z) allows for detailed assessment of mucosal pit and vascular pattern, magnifying images by factors greater than 100 with resolutions smaller than $7.9 \mu \mathrm{m}$ (17-19). Narrow band imaging (NBI) relies on specific wavelengths of light to produce a sharper contrast between mucosal and vascular structures enhancing detail $(20,21)$. NBI endoscopes enable the endoscopist to easily switch from WLE to NBI to optimize visualization and sampling.

Standard WLE mucosal appearances often correlate poorly with histology and there is no widely accepted consensus on the macroscopic appearance, therefore, clinicians are reliant on histology which is dependent on multiple factors such as biopsy area, biopsy numbers and experience of the histopathologist $(22,23)$. Anagnostopoulos et al proposed a classification using WLE-Z which was highly accurate for detecting normal, H. pylori gastritis and gastric atrophy with sensitivity and specificity of $90-100 \%$. Using this classification a normal gastric corpus microvasculature consists of a honeycomb type sub epithelial capillary network (SECN) with a regular arrangement of collecting venules and round pits. In the inflamed corpus, the normal SECN pattern and collecting venules are lost with enlarged white pits surrounded by erythema. Gastric atrophy is characterized by loss of the normal SECN and round pits, with an irregular distribution of collecting venules (18). Pimentel et al described a more detailed NBI classification that also included intestinal metaplasia and dysplasia with accuracy of $84 \%$ and 95\% respectively (24). The light blue crest (blue-whitish patchy reflections sited on the epithelial margins) appearance in magnified NBI (NBI-Z) of gastric mucosa was first described by Uedo et al and correlated well to intestinal metaplasia with an accuracy of 91\% (25). White Opaque Substance (WOS) is also sometimes associated with epithelial tumors and intestinal metaplasia 
(26). The use of NBI in the detection of these conditions was also accurate in other studies but due to study limitations reported results vary (27-30).

IgG ELISA serology detects $H$. pylori antibodies and is relatively cheap and non-invasive but a positive test cannot distinguish between current and previously treated infection. Accuracy is variable but some commercial kits report accuracy of greater than $90 \%$ (31) with the benefit that results are not affected by proton pump inhibitor (PPI) treatment.

Serum pepsinogen can be used to predict the extent of gastric atrophy. Pepsinogen I (PGI) and Pepsinogen II (PGII) are usually released from secretory cells found in the gastric mucosa. With the progression to atrophy this causes the loss of these secreting cells and reduces pepsinogen levels. PGI is more affected by this and thus the ratio is decreased further. Low pepsinogen I or pepsinogen I/II ratio less than 3 can signify moderate to severe corpus atrophy (13). For estimating gastric atrophy extent studies have described a huge variation in results with sensitivity and specificity from $9.4 \%$ to $92.3 \%$ and $9.9 \%$ to $100 \%$ respectively $(13,32-34)$. Serological markers of gastric atrophy are not routinely used in Western countries.

No study has yet evaluated the utility of both magnified narrow band imaging and serology in the detection of premalignant gastric pathology. Patients referred for endoscopic investigation for iron deficiency anemia were selected for this study due to the association with both $H$. pylori and gastric atrophy $(6,35,36)$. The Anagnostopoulos et al classification was adapted to use NBI-Z rather than WLE-Z in this study and termed the Nottingham classification.

The primary aim of this pilot study was to assess the diagnostic accuracy of magnified NBI endoscopy and serology in diagnosing normal mucosa, H. pylori gastritis and gastric atrophy using the Nottingham classification. Secondary aims were to compare the diagnostic accuracies of two validated classification systems using both NBI-Z and WLE-Z and evaluate the interobserver agreement.

\section{Material and Methods}

\section{Participants and clinical samples}

150 adult patients (18-85yrs) attending Nottingham University Hospitals (NUH) NHS Trust for a diagnostic gastroscopy as part of their investigation into iron deficiency anemia were 
prospectively recruited between August 2010 and December 2014. Derbyshire Research Ethical Committee (REC Ref: 10/H0401/33) approved the protocol and written informed consent was gained. Patients with low hemoglobin $(<130 \mathrm{~g} / 1$ men $\&<120 \mathrm{~g} / 1$ women $)$ and either a low MCV $(<84 \mathrm{fl})$ or low ferritin $(<25 \mathrm{mcg} / 1 \mathrm{men} \&<13 \mathrm{mcg} / 1$ women $)$ were recruited. Patients taking anticoagulants and proton pump inhibitors or individuals for whom biopsy sampling was contraindicated were not recruited. Patients who had an overt cause for iron deficiency anemia after both upper and lower GI investigations (e.g. malignancy $(n=22)$, coeliac disease $(n=9)$, poor quality digital images $(n=2)$ or patients without biopsies $(n=1))$ were excluded. 116 patients were included in the final analysis.

\section{Laboratory Investigations}

Fasting blood samples were collected and analyzed for full blood count, B12, folate, serum ferritin, transferrin saturation, transferrin, serum iron and iron binding capacity. Plasma was also stored at $-80^{\circ} \mathrm{C}$ until processed for H. pylori IgG (Biohit), PG I (Biohit) and PG II (Biohit) with ELISA kits according to manufacturer's instructions.

\section{Endoscopy procedures}

Procedures were performed by expert endoscopists using pharyngeal local anaesthetic spray Xylocaine (AstraZeneca, Luton, UK) or conscious sedation (midazolam/pethidine) according to patient preference. A black soft rubber hood (MB46, MAJ-1990, Olympus) was attached to the endoscope tip to allow a fixed $2 \mathrm{~mm}$ distance between gastric mucosa and gastroscope. All procedures were done with high definition and magnification Gastroscopes (GIF-FQ260Z; Olympus Optical, Tokyo, Japan) and Lucera Elite CV290 video processor. The video images were viewed on a high definition video monitor (OEV-191H, Olympus). During the procedure the mucosa was washed with a mixture containing $100 \mathrm{ml}$ of water mixed with $2 \mathrm{ml}$ of acetylcysteine $(200 \mathrm{mg} / \mathrm{ml}$, Parvolex, Celltech, UK) and 0.5ml (40mg/ml) dimethicone (Infacol, Forrest Laboratories, UK). Detailed examination of the gastric mucosa was then carried out, in WLE and then NBI using both low magnification and magnified views. Still digital images were recorded in both WLE and NBI, with biopsies taken from the areas where the digital images were recorded. A minimum of 8 images were recorded for each patient. All still images were transferred to an external hard drive. 


\section{Post endoscopy image production}

Images were stored as JPEG files (200-300 kilobytes, 1093x948 pixels, 32-bit color), edited, anonymized and given random numbers generated in Excel Office 2010 (Microsoft Corporation, Redmond, Washington, USA) before transfer into an evaluation set of folders according to area and classification system. Two principal endoscopists (Ragunath/Sami), experts in advanced endoscopy, agreed on the magnified appearance of each selected images of the gastric mucosa in WLE-Z and NBI-Z according to specific criteria. Both were blinded to clinical, histological and serological findings. Images were reviewed and graded according to mucosal morphology using the classifications described below. These scores were used to assess magnification endoscopy performance in terms of sensitivity, specificity, accuracy, positive and negative likelihood ratios.

\section{Image classification}

Two validated classification systems were used for the gastric corpus: the Nottingham classification (Figure 1) (18) and a modified Pimentel-Nunes et al classification (24) to include gastric atrophy $(\mathrm{Db})$ termed the modified Porto classification (Table 1, Figure 2).

\section{Inter-observer variability study}

Eight blinded endoscopists assessed the digital still images: four experienced, fully accredited endoscopists (experts) and four trainee endoscopists (non-experts). Prior to grading the images all endoscopists underwent a comprehensive, self-directed training package which covered all the gastric mucosa classifications. Each endoscopist viewed folders containing WLE-Z and NBI$\mathrm{Z}$ images of the corpus for both classifications. Approximately 464 anonymized randomized images were reviewed over an unrestricted length of time. Data on image classification from a drop down menu of pre-defined options and image quality according to a 10 point Visual Analogue Scale (VAS) (37) were recorded onto an Excel spreadsheet.

\section{Histopathology analysis}

Two gastric antrum, two gastric corpus and four duodenal samples were fixed in formalin, then embedded in paraffin and cut into approximately $4 \mu \mathrm{m}$ sections. Sections were stained with 
haematoxalin and eosin (H\&E) to allow histological scores to be carried out according to the updated Sydney scoring system (38). All specimens were classified as none (0), mild (1), moderate (2) or severe (3) for the following histological features activity (polymorphonuclear cell infiltration), inflammation (mononuclear cell infiltration), atrophy (loss of specialized glands) and intestinal metaplasia (replacement gastric mucosa by metaplastic columnar absorptive cells and goblet cells with intestinal morphologic features). Toluidine blue staining was also carried out for $H$. pylori density grading. A single blinded expert GI histopathologist carried out the histological grading. One biopsy from the antrum was placed in urease medium for rapid urease detection, and another sample in iso-sensitest broth (Oxoid, Cambridge, $\mathrm{UK}) / 10 \%$ glycerol for $H$. pylori isolation and culture.

\section{Statistical methods}

Sensitivity, specificity, positive and negative likelihood ratios along with $95 \%$ confidence intervals (CI) for magnification endoscopy appearances and serological markers were compared with histology. A receiver operating characteristic (ROC) curve was used to assess the diagnostic accuracy. Chi-squared tests were used to compare the diagnostic accuracies. Kappa (k) statistics were calculated to determine inter-rater agreement among experts and non-experts. Interpretation of $\mathrm{k}$ values was as follows: $<0=$ no agreement; $0-0.20=$ slight agreement; $0.21-$ $0.40=$ fair agreement; $0.41-0.60=$ moderate agreement; $0.61-0.80=$ substantial agreement; and $0.81-1=$ almost perfect agreement (39). Differences in image quality were assessed using the Mann-Whitney U test. P values $<0.05$ were considered statistically significant. Stata version 14 (Stata Corporation, College Station, Texas) was used for the statistical analysis.

\section{Results}

Patient characteristics are described in Table 2. 24\% of patients had histological evidence of $H$. pylori infection, $35 \%$ had gastric atrophy and $14.7 \%$ had intestinal metaplasia.

\section{Diagnostic accuracy of NBI-Z and serology}

NBI-Z diagnostic accuracy for determining normal corpus (Type I) was 0.87 (95\% CI 0.820.92), H. pylori gastritis (Type II/III) 0.65 (95\% CI 0.55-0.75) and gastric atrophy (Type IV) 0.88 (95\% CI 0.81-0.94) respectively. 
When NBI-Z was compared with serology, NBI-Z was superior for detecting gastric atrophy: NBI-Z Type IV 0.88 (95\% CI 0.81-0.94) vs PG I/II ratio <3 0.74 (95\% CI 0.62-0.85), p<0.0001

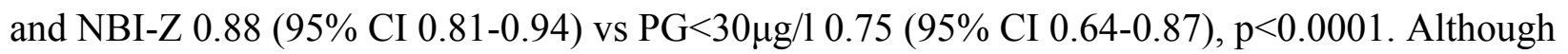
H. pylori IgG had a numerically higher accuracy this did not achieve statistical significance, NBI-Z Type II/III 0.65 (95\% CI 0.55-0.75) vs H. pylori IgG 0.82 (0.73-0.9), p=0.078.

\section{Diagnostic accuracy of NBI-Z and WLE-Z}

Using the Nottingham classification, NBI-Z performed better than WLE-Z for detecting normal corpus and gastric atrophy. Normal corpus (Type I): NBI-Z 0.87 (95\% CI 0.82-0.92) vs WLE-Z 0.82 (95\% CI 0.76-0.87), p<0.0001. Atrophy (Type IV): NBI-Z 0.88 (95\% CI 0.81-0.94) vs WLE-Z 0.81 (95\% CI 0.73-0.89), p<0.0001. However, WLE-Z performed better than NBI-Z for detecting H. pylori gastritis: NBI-Z 0.65 (CI 0.55-0.75) vs 0.69 (95\% CI 0.6-0.79), p<0.0001. (Table 3).

\section{Diagnostic accuracy of the Modified Porto classification}

NBI was more accurate than WLE for detecting normal mucosa, $H$. pylori gastritis and atrophy in the corpus. Normal corpus (Ab): NBI-Z 0.81 (95\% CI 0.74-0.87) vs WLE-Z 0.79 (95\% CI 0.72-0.87), $\mathrm{p}<0.0001$. H. pylori gastritis $(\mathrm{Ab}+)$ : NBI-Z 0.77 (95\% CI 0.67-0.87) vs WLE-Z 0.62 (95\% CI 0.51-0.74), $\mathrm{p}=0.01$. Gastric atrophy (Db): NBI-Z 0.71 (95\% CI 0.62-0.79) vs WLE-Z 0.65 (95\% CI 0.56-0.73), $\mathrm{p}<0.0001$. For detecting intestinal metaplasia, there was no statistical difference in accuracy. Intestinal metaplasia (Bb): NBI-Z 0.66 (95\% CI 0.53-0.79) vs WLE-Z 0.59 (95\% CI 0.45-0.73), $\mathrm{p}=0.28$. (Table 4).

\section{Inter-observer agreement}

The mean kappa values for inter-observer agreement for NBI endoscopy images were higher among expert than non-experts endoscopists. For describing the corpus using the Nottingham classification the agreement was $0.63(95 \%$ CI $0.51-0.73)$ vs 0.5 (95\% CI 0.39-0.62). When describing atrophy the agreement was 0.65 (95\% CI $0.53-0.75)$ vs 0.47 (95\% CI 0.2-0.68). Using the modified Porto classification when describing the corpus was 0.33 (95\% CI $0.21-0.43$ ) vs 0.2 (95\% CI 0.12-0.28). When describing intestinal metaplasia the agreement was 0.36 (95\% CI 
0.24-0.47) vs 0.21 (95\% CI 0.1-0.34). Both expert and non-expert endoscopists rated the overall image quality VAS higher for NBI than WLE (7 vs $6 \mathrm{p}<0.0001)$.

\section{Discussion}

Standard WLE is limited in its ability to accurately diagnose gastric lesions, which has led to the development of a variety of techniques such as chromoendoscopy, NBI, flexible spectral imaging color enhancement (FICE), autofluorescence (AFI) and confocal laser endomicroscopy (19) in addition to gold standard histology. NBI has been extensively studied for its use in detecting dysplasia in the esophagus, bronchus and in colonic polyps $(19,40-42)$.

We conducted this pilot study to assess the role of NBI and serology in predicting the histological diagnosis of gastric mucosa. We demonstrated good correlation with normal and gastric atrophy using magnification endoscopy. However, for detecting $H$. pylori gastritis our results were limited with an accuracy of 0.65 using the Nottingham classification. Endoscopic diagnosis of $H$. pylori infection requires a subjective assessment of vascular density of subepithelial capillary network (SECN). A more objective and accurate measurement may be needed to increase accuracy. Overall, NBI-Z performed better than both WLE-Z and serological markers for predicting disease. This was the first study to compare NBI-Z and serological markers with gastric pathology.

The main factor influencing NBI appearance is light absorption by hemoglobin within blood vessels which in turn leads to variation in the vascular pattern of the gastric mucosa. The differences seen in gastric mucosa using NBI are a true reflection of the structural differences seen in vitro histologically. This in turn allows NBI to predict histological diagnosis (43). The endoscopic appearance of gastric atrophy has been established since the 1970's (44). The normal gastric body consists of a regular pattern of honeycomb type SECN and collecting venules but in H. pylori gastritis this is irregular and accompanied by surrounding edema $(18,45)$.

Very few studies have investigated the endoscopic appearance of $H$. pylori gastritis, with nodular mucosal and gastric fold hypertrophy the most consistent features despite low sensitivities when compared to histology $(46,47)$. Thus the exact features that describe $H$. pylori gastritis are not entirely known which makes description and interpretation difficult. The findings using the Nottingham classification were lower than when initially described using WLE (18). Potential 
reasons for this include the fact that the principal endoscopists scoring the images did not perform the procedures and, therefore, were blinded to potential clinical information that could influence decision making. Although the modified Porto classification required more time to examine the images it also offered more details in terms of the presence of intestinal metaplasia and dysplasia. The specificity was high for normal mucosa, gastric atrophy and intestinal metaplasia. Potentially this could enable endoscopists to confidently avoid taking biopsies in the corpus. The evidence for the use magnified endoscopy in detecting other disease shows the majority have good correlation with histology $(18,28,48-50)$. Currently, the gold standard for the diagnosis of intestinal metaplasia and dysplasia remains histology despite promising results with NBI.

When compared with serological markers, NBI-Z overall performed better. Previous studies have also shown that NBI is accurate in detecting premalignant lesions $(29,30,51)$. The serological data presented in this study was similar to previous studies in terms of sensitivity and specificity $(13,31,52,53)$. H. pylori serology is commonly used in clinical practice in the UK but markers of atrophy are not. These results suggest the PG I/II ratio or PG I alone cannot replace endoscopy surveillance or detection of gastric atrophy. However, using this in clinical practice could reduce the need to obtain histology if serology is negative and NBI-Z does not suggest disease, therefore, reducing associated costs and time.

Inter-observer agreement was unsurprisingly higher among expert endoscopists when compared with non-experts. Endoscopy assessment is dependent on experience and training, so these techniques are likely to perform better in the hands of experts $(54,55)$. The training of western endoscopists is also likely to be different compared to Asian countries where the incidence of gastric cancer is higher. The observers VAS median scores were higher for NBI-Z than WLE-Z suggesting NBI provided more clarity to enable a diagnosis.

Our results are more applicable to specialist centers that routinely use NBI endoscopy as it requires a certain skill level and so may not always be practical to use in routine clinical practice. In the same way, the captured images in this study were captured by endoscopists with advanced diagnostic imaging experience and this is unlikely to happen routinely. As shown by the lower agreement amongst non-experts, NBI requires training in mucosal pattern recognition. The main comparison was done with experts so if this was used in a real world setting the results may be 
poorer. Also the time duration each endoscopist spent reviewing the still images for the interobserver study was not specified and unlike time constraints seen in clinical practice, possibly influencing the decision making process. In terms of training, this study did not measure interobserver agreement before and after the training session which would have given some insight into the learning required for NBI use in a routine clinical setting.

Study strengths include the use of two endoscopy classification criteria to describe the magnified gastric mucosa in addition to serological markers in a large cohort of prospectively recruited patients. Post endoscopy image assessment controlled for clinician influence on pre-test probability. Bias was also reduced by blinding both the endoscopists and histopathologist to clinical data. Also the consistent use of the same gastroscope reduced image quality variability. Patients on proton pump inhibitors were also excluded to lower the number of false negatives in terms of $H$. pylori infection and to avoid missing early gastric neoplasia (56). This work has provided further evidence to support routinely investigating the presence of gastric atrophy and H. pylori gastritis in iron deficiency anemia patients $(31,36)$.

With regards to study limitations, by including only iron deficiency anemia patients this makes the study prone to selection bias and thus may not be representative at a population scale. However, as the annual incidence of gastric atrophy is low (0-10.9\%) (57) we needed a larger cohort to enable estimates of sensitivity and specificity to be made to guide sample size calculations in future larger studies. Extent of disease also influenced the results. For example, atrophy serology tests only detect moderate to severe atrophy so endoscopy is more likely to perform better as these classifications only detect the presence of atrophy and not the degree. Inter-observer agreement for the modified Porto classification may also be lower due to the examiners been more familiar with the Nottingham classification at this specialist center. Finally, although the addition of atrophy to the modified Porto classification provided a more detailed description which more accurately resembled histology it also made the classification more complex and time consuming. The diagnosis of intestinal metaplasia is more reliable in terms of both histological grading and disease progression.

In conclusion, NBI-Z can detect changes in the GI mucosa which are usually dependent on histology. Although serology performs well, NBI endoscopy performs better in terms of disease detection with a high specificity and moderate to substantial observer agreement. A detailed 
examination with NBI-Z could potentially help identify early precancerous lesions, which could enable patients to be promptly enrolled in appropriate endoscopic surveillance with improved disease outcomes. Also NBI-Z use may allow stratification of the need for histology and thus minimize associated costs, time and sampling error. These study findings will help to design future trials to evaluate NBI techniques in the gastric mucosa.

\section{Acknowledgements}

We would like to thank the faculty staff especially Samantha Warburton, Susan Henry and Melanie Lingaya and equipment support provided by the NIHR Nottingham Digestive Diseases Biomedical Research Centre, Nottingham, United Kingdom. This article presents independent research supported by the National Institute for Health Research (NIHR). The views expressed are those of the author(s) and not necessarily those of the NHS, the NIHR, or the Department of Health.

\section{Disclosure statement}

Financial support: This work was supported by the National Institute for Health Research Biomedical Research Centre, United Kingdom.

The authors report no conflict of interest.

\section{References}

1. Pounder RE, Ng D. The prevalence of Helicobacter pylori infection in different countries. Alimentary pharmacology \& therapeutics. 1995;9 Suppl 2:33-9. PubMed PMID: 8547526. 
2. Peleteiro B, Bastos A, Ferro A, et al. Prevalence of Helicobacter pylori infection worldwide: a systematic review of studies with national coverage. Digestive diseases and sciences. 2014 Aug;59(8):1698-709. PubMed PMID: 24563236.

3. Blaser MJ, Atherton JC. Helicobacter pylori persistence: biology and disease. The Journal of clinical investigation. 2004 Feb;113(3):321-33. PubMed PMID: 14755326. Pubmed Central PMCID: 324548 .

4. Atherton JC. The pathogenesis of Helicobacter pylori-induced gastro-duodenal diseases. Annual review of pathology. 2006;1:63-96. PubMed PMID: 18039108.

5. Franchini M, Veneri D. Helicobacter pylori infection and immune thrombocytopenic purpura: an update. Helicobacter. 2004 Aug;9(4):342-6. PubMed PMID: 15270749.

6. $\quad \mathrm{Qu}$ XH, Huang XL, Xiong P, et al. Does Helicobacter pylori infection play a role in iron deficiency anemia? A meta-analysis. World journal of gastroenterology : WJG. 2010 Feb 21;16(7):88696. PubMed PMID: 20143469. Pubmed Central PMCID: 2825337.

7. Strachan DP. Hay fever, hygiene, and household size. BMJ. 1989 Nov 18;299(6710):1259-60. PubMed PMID: 2513902. Pubmed Central PMCID: 1838109.

8. Rugge M, Correa P, Dixon MF, et al. Gastric mucosal atrophy: interobserver consistency using new criteria for classification and grading. Alimentary pharmacology \& therapeutics. 2002 Jul;16(7):1249-59. PubMed PMID: 12144574.

9. Correa P. Helicobacter pylori and gastric carcinogenesis. The American journal of surgical pathology. 1995;19 Suppl 1:S37-43. PubMed PMID: 7762738.

10. O'Connor A, McNamara D, O'Morain CA. Surveillance of gastric intestinal metaplasia for the prevention of gastric cancer. The Cochrane database of systematic reviews. 2013;9:CD009322. PubMed PMID: 24062262.

11. de Vries AC, van Grieken NC, Looman CW, et al. Gastric cancer risk in patients with premalignant gastric lesions: a nationwide cohort study in the Netherlands. Gastroenterology. 2008 Apr;134(4):945-52. PubMed PMID: 18395075.

12. den Hoed CM, Holster IL, Capelle LG, et al. Follow-up of premalignant lesions in patients at risk for progression to gastric cancer. Endoscopy. 2013;45(4):249-56. PubMed PMID: 23533073.

13. Dinis-Ribeiro M, Areia M, de Vries AC, et al. Management of precancerous conditions and lesions in the stomach (MAPS): guideline from the European Society of Gastrointestinal Endoscopy (ESGE), European Helicobacter Study Group (EHSG), European Society of Pathology (ESP), and the Sociedade Portuguesa de Endoscopia Digestiva (SPED). Endoscopy. 2012 Jan;44(1):74-94. PubMed PMID: 22198778. Pubmed Central PMCID: 3367502.

14. de Vries AC, Haringsma J, Kuipers EJ. The detection, surveillance and treatment of premalignant gastric lesions related to Helicobacter pylori infection. Helicobacter. 2007 Feb;12(1):1-15. PubMed PMID: 17241295.

15. Colquhoun A, Arnold M, Ferlay J, et al. Global patterns of cardia and non-cardia gastric cancer incidence in 2012. Gut. 2015 Mar 6. PubMed PMID: 25748648.

16. Herrero R, Park JY, Forman D. The fight against gastric cancer - the IARC Working Group report. Best practice \& research Clinical gastroenterology. 2014 Dec;28(6):1107-14. PubMed PMID: 25439075.

17. Yao K, Oishi T, Matsui T, et al. Novel magnified endoscopic findings of microvascular architecture in intramucosal gastric cancer. Gastrointestinal endoscopy. 2002 Aug;56(2):279-84. PubMed PMID: 12145613.

18. Anagnostopoulos GK, Yao K, Kaye P, et al. High-resolution magnification endoscopy can reliably identify normal gastric mucosa, Helicobacter pylori-associated gastritis, and gastric atrophy. Endoscopy. 2007 Mar;39(3):202-7. PubMed PMID: 17273960.

19. Subramanian V, Ragunath K. Advanced endoscopic imaging: a review of commercially available technologies. Clinical gastroenterology and hepatology : the official clinical practice journal of the American Gastroenterological Association. 2014 Mar;12(3):368-76 e1. PubMed PMID: 23811245. 
20. Gono K, Obi T, Yamaguchi M, et al. Appearance of enhanced tissue features in narrow-band endoscopic imaging. Journal of biomedical optics. 2004 May-Jun;9(3):568-77. PubMed PMID: 15189095.

21. Yoshida T, Inoue H, Usui S, et al. Narrow-band imaging system with magnifying endoscopy for superficial esophageal lesions. Gastrointestinal endoscopy. 2004 Feb;59(2):288-95. PubMed PMID: 14745410.

22. Redeen S, Petersson F, Jonsson KA, et al. Relationship of gastroscopic features to histological findings in gastritis and Helicobacter pylori infection in a general population sample. Endoscopy. 2003 Nov;35(11):946-50. PubMed PMID: 14606018.

23. Gonen C, Simsek I, Sarioglu S, et al. Comparison of high resolution magnifying endoscopy and standard videoendoscopy for the diagnosis of Helicobacter pylori gastritis in routine clinical practice: a prospective study. Helicobacter. 2009 Feb;14(1):12-21. PubMed PMID: 19191891.

24. Pimentel-Nunes P, Dinis-Ribeiro M, Soares JB, et al. A multicenter validation of an endoscopic classification with narrow band imaging for gastric precancerous and cancerous lesions. Endoscopy. 2012 Mar;44(3):236-46. PubMed PMID: 22294194.

25. Uedo $\mathrm{N}$, Ishihara $\mathrm{R}$, Iishi $\mathrm{H}$, et al. A new method of diagnosing gastric intestinal metaplasia: narrow-band imaging with magnifying endoscopy. Endoscopy. 2006 Aug;38(8):819-24. PubMed PMID: 17001572 .

26. Yao K, Iwashita A, Nambu M, et al. Nature of white opaque substance in gastric epithelial neoplasia as visualized by magnifying endoscopy with narrow-band imaging. Digestive endoscopy : official journal of the Japan Gastroenterological Endoscopy Society. 2012 Nov;24(6):419-25. PubMed PMID: 23078433.

27. Curvers WL, van den Broek FJ, Reitsma JB, et al. Systematic review of narrow-band imaging for the detection and differentiation of abnormalities in the esophagus and stomach (with video). Gastrointestinal endoscopy. 2009 Feb;69(2):307-17. PubMed PMID: 19185690.

28. Tahara T, Shibata T, Nakamura M, et al. Gastric mucosal pattern by using magnifying narrowband imaging endoscopy clearly distinguishes histological and serological severity of chronic gastritis. Gastrointestinal endoscopy. 2009 Aug;70(2):246-53. PubMed PMID: 19386303.

29. Capelle LG, Haringsma J, de Vries AC, et al. Narrow band imaging for the detection of gastric intestinal metaplasia and dysplasia during surveillance endoscopy. Digestive diseases and sciences. 2010 Dec;55(12):3442-8. PubMed PMID: 20393882. Pubmed Central PMCID: 2975908.

30. Pimentel-Nunes P, Libanio D, Lage J, et al. A multicenter prospective study of the real-time use of narrow-band imaging in the diagnosis of premalignant gastric conditions and lesions. Endoscopy. 2016 Jun 9. PubMed PMID: 27280384.

31. Malfertheiner P, Megraud F, O'Morain CA, et al. Management of Helicobacter pylori infection-the Maastricht IV/ Florence Consensus Report. Gut. 2012 May;61(5):646-64. PubMed PMID: 22491499.

32. Inoue M, Kobayashi S, Matsuura A, et al. Agreement of endoscopic findings and serum pepsinogen levels as an indicator of atrophic gastritis. Cancer epidemiology, biomarkers \& prevention : a publication of the American Association for Cancer Research, cosponsored by the American Society of Preventive Oncology. 1998 Mar;7(3):261-3. PubMed PMID: 9521444.

33. Graham DY, Nurgalieva ZZ, El-Zimaity HM, et al. Noninvasive versus histologic detection of gastric atrophy in a Hispanic population in North America. Clinical gastroenterology and hepatology : the official clinical practice journal of the American Gastroenterological Association. 2006 Mar;4(3):306-14. PubMed PMID: 16527693.

34. Leja M, Kupcinskas L, Funka K, et al. The validity of a biomarker method for indirect detection of gastric mucosal atrophy versus standard histopathology. Digestive diseases and sciences. 2009 Nov;54(11):2377-84. PubMed PMID: 19731026.

35. Goddard AF, James MW, McIntyre AS, et al. British Society of G. Guidelines for the management of iron deficiency anaemia. Gut. 2011 Oct;60(10):1309-16. PubMed PMID: 21561874. 
36. Kaye PV, Garsed K, Ragunath K, et al. The clinical utility and diagnostic yield of routine gastric biopsies in the investigation of iron deficiency anemia: a case-control study. The American journal of gastroenterology. 2008 Nov;103(11):2883-9. PubMed PMID: 18775015.

37. Likert R. A technique for the measurement of attitudes. New York,1932. 55 p. p.

38. Dixon MF, Genta RM, Yardley JH, et al. Classification and grading of gastritis. The updated Sydney System. International Workshop on the Histopathology of Gastritis, Houston 1994. The American journal of surgical pathology. 1996 Oct;20(10):1161-81. PubMed PMID: 8827022.

39. Landis JR, Koch GG. The measurement of observer agreement for categorical data. Biometrics. 1977 Mar;33(1):159-74. PubMed PMID: 843571.

40. Sharma P, Bansal A, Mathur S, et al. The utility of a novel narrow band imaging endoscopy system in patients with Barrett's esophagus. Gastrointestinal endoscopy. 2006 Aug;64(2):167-75. PubMed PMID: 16860063.

41. Shibuya K, Hoshino H, Chiyo M, et al. High magnification bronchovideoscopy combined with narrow band imaging could detect capillary loops of angiogenic squamous dysplasia in heavy smokers at high risk for lung cancer. Thorax. 2003 Nov;58(11):989-95. PubMed PMID: 14586056. Pubmed Central PMCID: 1746520.

42. Machida H, Sano Y, Hamamoto Y, et al. Narrow-band imaging in the diagnosis of colorectal mucosal lesions: a pilot study. Endoscopy. 2004 Dec;36(12):1094-8. PubMed PMID: 15578301. 43. Bansal A, Ulusarac O, Mathur S, et al. Correlation between narrow band imaging and nonneoplastic gastric pathology: a pilot feasibility trial. Gastrointestinal endoscopy. 2008 Feb;67(2):2106. PubMed PMID: 18226682.

44. Sakaki N, Iida Y, Okazaki Y, et al. Magnifying endoscopic observation of the gastric mucosa, particularly in patients with atrophic gastritis. Endoscopy. 1978 Nov;10(4):269-74. PubMed PMID: 738222.

45. Yagi K, Nakamura A, Sekine A. Characteristic endoscopic and magnified endoscopic findings in the normal stomach without Helicobacter pylori infection. Journal of gastroenterology and hepatology. 2002 Jan;17(1):39-45. PubMed PMID: 11895551.

46. Laine L, Cohen H, Sloane R, et al. Interobserver agreement and predictive value of endoscopic findings for H. pylori and gastritis in normal volunteers. Gastrointestinal endoscopy. 1995 Nov;42(5):420-3. PubMed PMID: 8566631.

47. Yela MC, Manzano ML, Rodriguez-Munoz S, et al. Assessment of the usefulness of endoscopic signs in Helicobacter pylori associated gastritis. Revista espanola de enfermedades digestivas : organo oficial de la Sociedad Espanola de Patologia Digestiva. 1997 Jan;89(1):3-12. PubMed PMID: 9055583. 48. Eshmuratov A, Nah JC, Kim N, et al. The correlation of endoscopic and histological diagnosis of gastric atrophy. Digestive diseases and sciences. 2010 May;55(5):1364-75. PubMed PMID: 19629687. 49. Yan SL, Wu ST, Chen CH, et al. Mucosal patterns of Helicobacter pylori-related gastritis without atrophy in the gastric corpus using standard endoscopy. World journal of gastroenterology : WJG. 2010 Jan 28;16(4):496-500. PubMed PMID: 20101778. Pubmed Central PMCID: 2811805.

50. Liu $\mathrm{H}, \mathrm{Wu} \mathrm{J}$, Lin XC, et al. Evaluating the diagnoses of gastric antral lesions using magnifying endoscopy with narrow-band imaging in a Chinese population. Digestive diseases and sciences. 2014 Jul;59(7):1513-9. PubMed PMID: 24488235.

51. Ang TL, Pittayanon R, Lau JY, et al. A multicenter randomized comparison between highdefinition white light endoscopy and narrow band imaging for detection of gastric lesions. European journal of gastroenterology \& hepatology. 2015 Dec;27(12):1473-8. PubMed PMID: 26426836.

52. Leffler DA, Schuppan D. Update on serologic testing in celiac disease. The American journal of gastroenterology. 2010 Dec;105(12):2520-4. PubMed PMID: 21131921.

53. Zagari RM, Rabitti S, Greenwood DC, et al. Systematic review with meta-analysis: diagnostic performance of the combination of pepsinogen, gastrin-17 and anti-Helicobacter pylori antibodies serum assays for the diagnosis of atrophic gastritis. Alimentary pharmacology \& therapeutics. 2017 Oct;46(7):657-67. PubMed PMID: 28782119. 
54. Basford P, Longcroft-Wheaton G, Bhandari P. ASGE Technology Committee reviews on realtime endoscopic assessment of the histology of diminutive colorectal polyps, and high-definition and high-magnification endoscopes. Gastrointestinal endoscopy. 2015 Dec;82(6):1139-40. PubMed PMID: 26614165.

55. Dias-Silva D, Pimentel-Nunes P, Magalhaes J, et al. The learning curve for narrow-band imaging in the diagnosis of precancerous gastric lesions by using Web-based video. Gastrointestinal endoscopy. 2014 Jun;79(6):910-20; quiz 83-e1, 83 e4. PubMed PMID: 24287281.

56. Bramble MG, Suvakovic Z, Hungin AP. Detection of upper gastrointestinal cancer in patients taking antisecretory therapy prior to gastroscopy. Gut. 2000 Apr;46(4):464-7. PubMed PMID: 10716673. Pubmed Central PMCID: 1727877.

57. Vannella L, Lahner E, Annibale B. Risk for gastric neoplasias in patients with chronic atrophic gastritis: a critical reappraisal. World journal of gastroenterology : WJG. 2012 Mar 28;18(12):1279-85. PubMed PMID: 22493541. Pubmed Central PMCID: 3319954. 

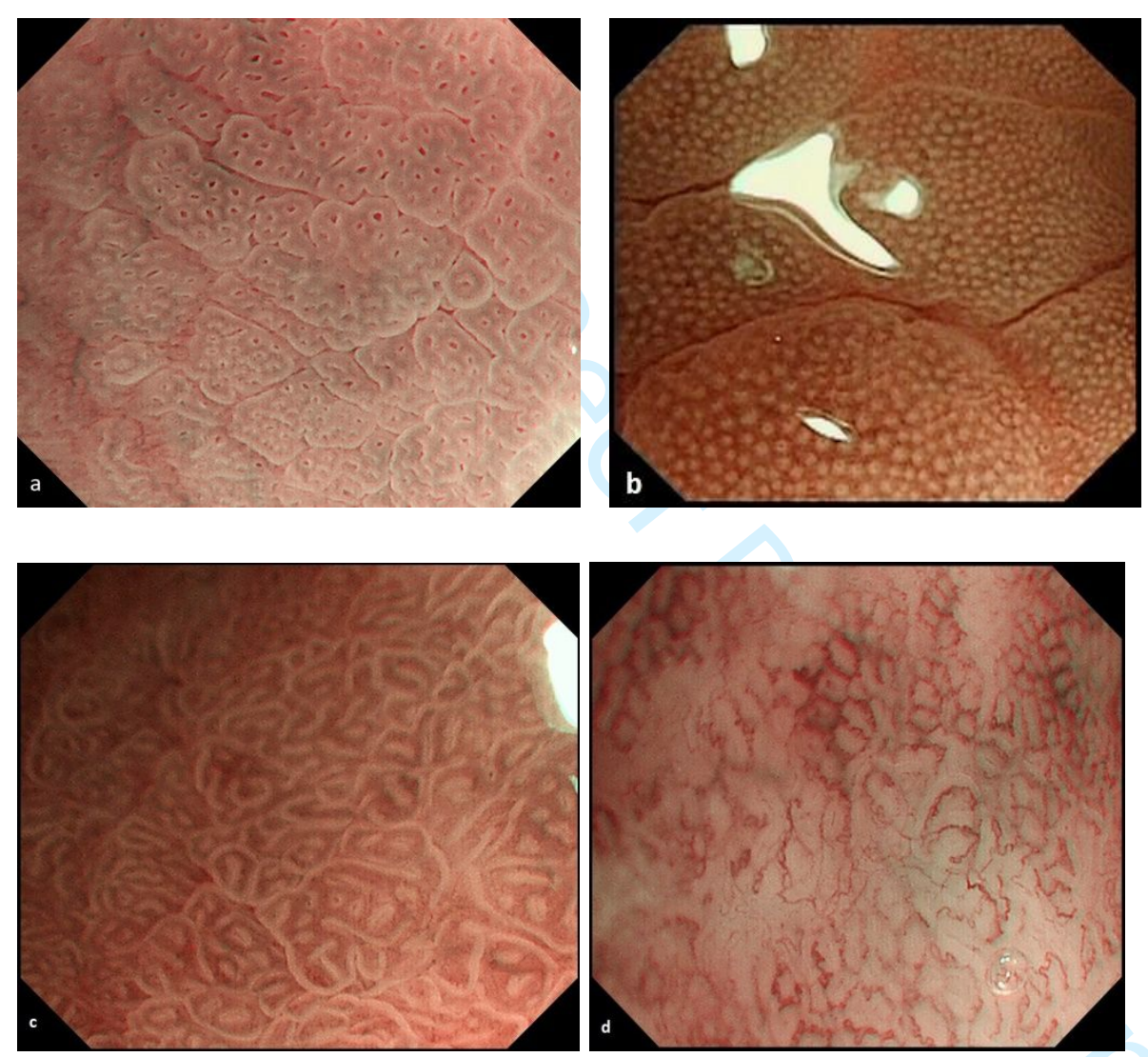

Figure 1 The Nottingham classification in gastric corpus

Type I (a) normal gastric body microvasculature = a honeycomb type subepithelial capillary network $(\mathrm{SECN})$ and collecting venules in a regular arrangement. Type II (b) = honeycomb-type SECN with regular round pits, either with or without sulci, but with loss of collecting venules. Type III (c) = loss of the normal SECN and collecting venules, with enlarged white pits surrounded by erythema. Type IV $(d)=$ loss of the normal SECN and round pits, with irregular arrangement of the collecting venules (18). 

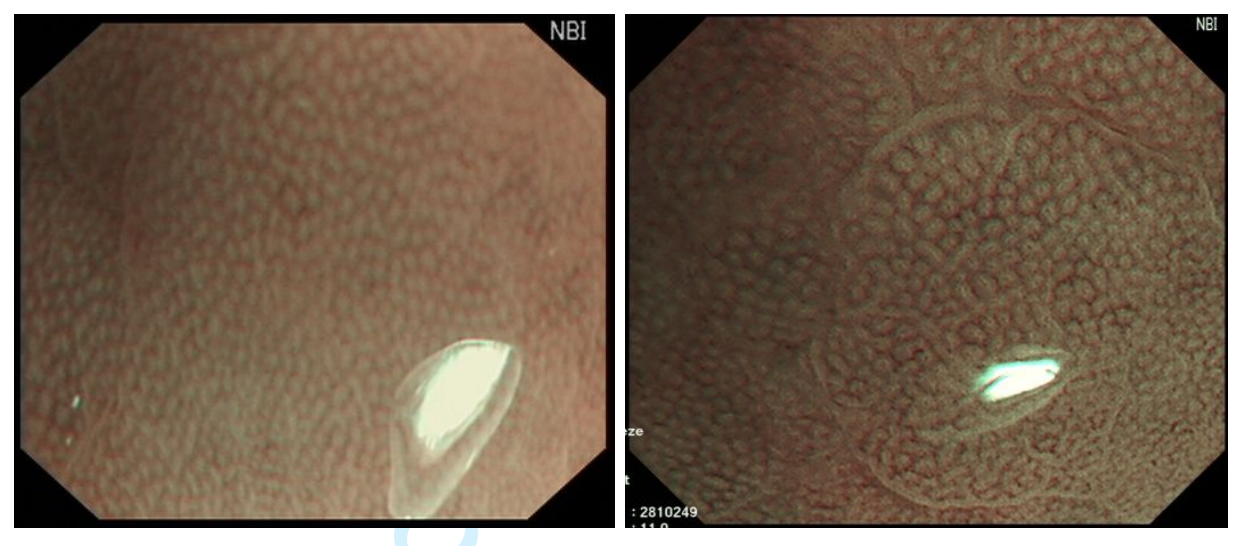

A

B
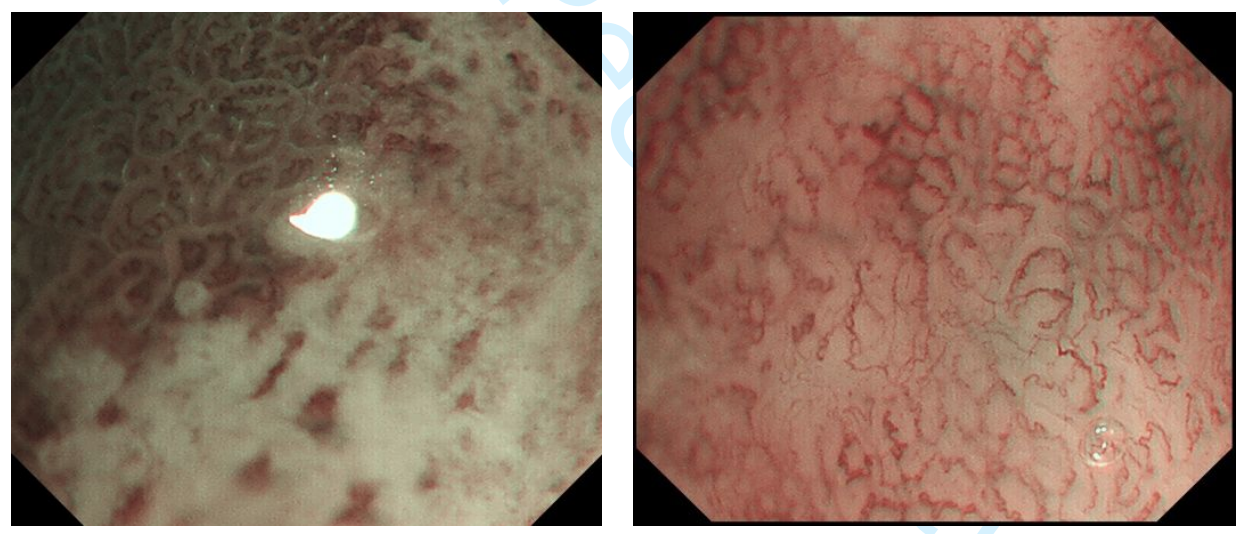

$\mathrm{C}$

$\mathrm{D}$

Figure 2 Modified Porto gastric corpus classification

Normal corpus (Ab) in image (A), (B) H. pylori gastritis corpus $(\mathrm{Ab}+)$, (intestinal metaplasia in corpus with some light blue crest $(\mathrm{Bb})$ in image $(\mathrm{C})$ and atrophy in corpus $(\mathrm{Db})$ in image $(\mathrm{D})$. Magnification $115 \mathrm{X}$. 
2

3

4

5

6

7

8

10

11

12

13

14

15

16

17

18

19

\section{Tables}

Table 1 Modified Porto classification

\begin{tabular}{|c|c|c|c|c|c|}
\hline & $\mathrm{A}^{*}$ & $\mathrm{~B}^{*}$ & H. pylori+ & $\mathrm{C}^{*}$ & $\mathrm{D}^{*}$ \\
\hline $\begin{array}{c}\text { Mucosal } \\
\text { pattern }\end{array}$ & $\begin{array}{c}\text { Regular } \\
\text { circular/oval }\end{array}$ & $\begin{array}{c}\text { Regular } \\
\text { Ridge/tubulo- } \\
\text { villous with } \\
\text { or without } \\
\text { light blue } \\
\text { crest }\end{array}$ & Regular & $\begin{array}{c}\text { Irregular/ } \\
\text { absent } \\
\text { with or } \\
\text { without } \\
\text { white } \\
\text { opaque } \\
\text { substance }\end{array}$ & Absent \\
\hline $\begin{array}{l}\text { Vascular } \\
\text { pattern } \\
(\mathrm{SECN})\end{array}$ & $\begin{array}{l}\text { Regular mucosa } \\
\text { and SECN } \\
\text { Vascular pattern } \\
\text { central in } \\
\text { antrum/peripheral } \\
\text { in corpus of gland }\end{array}$ & Regular & $\begin{array}{l}\text { Regular/ } \\
\text { variable } \\
\text { vascular } \\
\text { density }\end{array}$ & Irregular & Absent \\
\hline $\begin{array}{l}\text { Expected } \\
\text { outcome }\end{array}$ & Normal & $\begin{array}{l}\text { Intestinal } \\
\text { Metaplasia }\end{array}$ & $\begin{array}{l}\text { H. pylori } \\
\text { infection }\end{array}$ & Dysplasia & $\begin{array}{l}\text { Atrophic } \\
\text { gastritis }\end{array}$ \\
\hline
\end{tabular}

The letter (a) for antrum or (b) for corpus is added to the class type to signify the sites. For H. pylori positive pattern, the symbol $(+)$ is added to end of the pattern class site. For e.g. H. pylori positive pattern in corpus would be classed as $\mathrm{Ab}+(24)$. 
Table 2 Patient description and laboratory data

\begin{tabular}{|c|c|}
\hline Numbers & 116 \\
\hline Male: Female ratio & $1: 1.1$ \\
\hline Age, median (range) years & $67(19-85)$ \\
\hline $\begin{array}{c}\% \text { Pharyngeal local anesthetic: } \\
\text { conscious sedation }\end{array}$ & $38 \%: 62 \%$ \\
\hline Midazolam median dose (range) & $3 \mathrm{mg}(1-5)$ \\
\hline Pethidine median dose (range) & $25 \mathrm{mg}(25-100)$ \\
\hline $\begin{array}{l}\text { Hemoglobin males (130- } \\
180 \mathrm{~g} / \mathrm{L}) \text { median (range) }\end{array}$ & $110 \mathrm{~g} / \mathrm{L}(85-129)$ \\
\hline $\begin{array}{l}\text { Hemoglobin females (120- } \\
165 \mathrm{~g} / \mathrm{L}) \text { median (range) }\end{array}$ & $101 \mathrm{~g} / \mathrm{L}(42-118)$ \\
\hline MCV (84-102fl) median (range) & $83 \mathrm{fl}(56-111)$ \\
\hline $\begin{array}{l}\text { Ferritin }(25-350 \mu \mathrm{g} / \mathrm{L}) \text { median } \\
\text { (range) }\end{array}$ & $12 \mu \mathrm{g} / \mathrm{L}(1-474)$ \\
\hline $\begin{array}{c}\text { Iron }(9-31 \mu \mathrm{mol} / \mathrm{L}) \text { median } \\
(\text { range })\end{array}$ & $11 \mu \mathrm{mol} / \mathrm{L}(1-83)$ \\
\hline \multicolumn{2}{|l|}{ Histological diagnosis: } \\
\hline$\%$ H. pylori infection & $24 \%$ \\
\hline$\%$ Atrophy corpus & $35 \%$ \\
\hline$\%$ Intestinal metaplasia & $14.7 \%$ \\
\hline
\end{tabular}

Presented as median with full range 
Table 3 Sensitivity, specificity and likelihood ratios with 95\% CI of NBI-Z and WLE-Z for detecting $H$. pylori gastritis and gastric atrophy using the Nottingham classification and serology

\begin{tabular}{|c|c|c|c|c|}
\hline & Sensitivity (95\% CI) & $\begin{array}{c}\text { Specificity (95\% } \\
\text { CI) }\end{array}$ & $\begin{array}{c}\text { Positive } \\
\text { Likelihood } \\
\text { ratio (95\% CI) }\end{array}$ & $\begin{array}{c}\text { Negative } \\
\text { Likelihood } \\
\text { ratio (95\% CI) }\end{array}$ \\
\hline NBI-Z Type I & $75.6 \%(64.6-84.7)$ & $98.6 \%(92.2-100)$ & $54.0(7.4-$ & $0.25(0.17-$ \\
$366.8)$ & $0.37)$
\end{tabular}


Table 4 Sensitivity, specificity and likelihood ratios with $95 \%$ confidence intervals of NBI-Z and WLE-Z using the modified Porto classification in the corpus

\begin{tabular}{|c|c|c|c|c|}
\hline & Sensitivity $(95 \% \mathrm{CI})$ & $\begin{array}{l}\text { Specificity }(95 \% \\
\text { CI) }\end{array}$ & $\begin{array}{c}\text { Positive } \\
\text { Likelihood } \\
\text { ratio }(95 \% \mathrm{CI})\end{array}$ & $\begin{array}{c}\text { Negative } \\
\text { Likelihood } \\
\text { ratio }(95 \% \mathrm{CI})\end{array}$ \\
\hline NBI-Z Ab & $70.5 \%(59.8-79.7)$ & $90.9 \%(78.3-97.5)$ & $7.75(3-19.9)$ & $\begin{array}{c}0.32(0.23- \\
0.45)\end{array}$ \\
\hline WLE-Z Ab & $77.8 \%(66.4-86.7)$ & $81 \%(65.9-91.4)$ & $4.09(2.2-7.7)$ & $\begin{array}{c}0.27(0.17- \\
0.43)\end{array}$ \\
\hline NBI-Z Ab+ & $75 \%(53-90.2)$ & $78.7 \%(69.8-86)$ & $3.52(2.3-5.4)$ & $\begin{array}{c}0.32(0.16- \\
0.64)\end{array}$ \\
\hline WLE-Z Ab+ & $43.5 \%(23.2-65.5)$ & $81.3 \%(71.8-88.7)$ & $2.33(1.24-4.4)$ & $\begin{array}{c}0.69(0.48- \\
1.01)\end{array}$ \\
\hline NBI-Z Bb & $35.7 \%(12.8-64.9)$ & $95.8 \%(90.4-98.6)$ & $\begin{array}{c}8.43(2.78- \\
25.5)\end{array}$ & $\begin{array}{c}0.67(0.45- \\
0.99)\end{array}$ \\
\hline WLE-Z Bb & $27.3 \%(6-61)$ & $90.1 \%(82.5-95.1)$ & $\begin{array}{c}2.75(0.89- \\
8.53)\end{array}$ & $\begin{array}{c}0.81(0.56- \\
1.17)\end{array}$ \\
\hline NBI-Z Db & $70 \%(52-81)$ & $99 \%(94.5-100)$ & $\begin{array}{c}70.0(10.74- \\
307)\end{array}$ & $\begin{array}{c}0.30(0.23- \\
0.78)\end{array}$ \\
\hline WLE-Z Db & $61 \%(45-76)$ & $100 \%(95.7-100)$ & - & $\begin{array}{c}0.39(0.27- \\
0.50)\end{array}$ \\
\hline
\end{tabular}




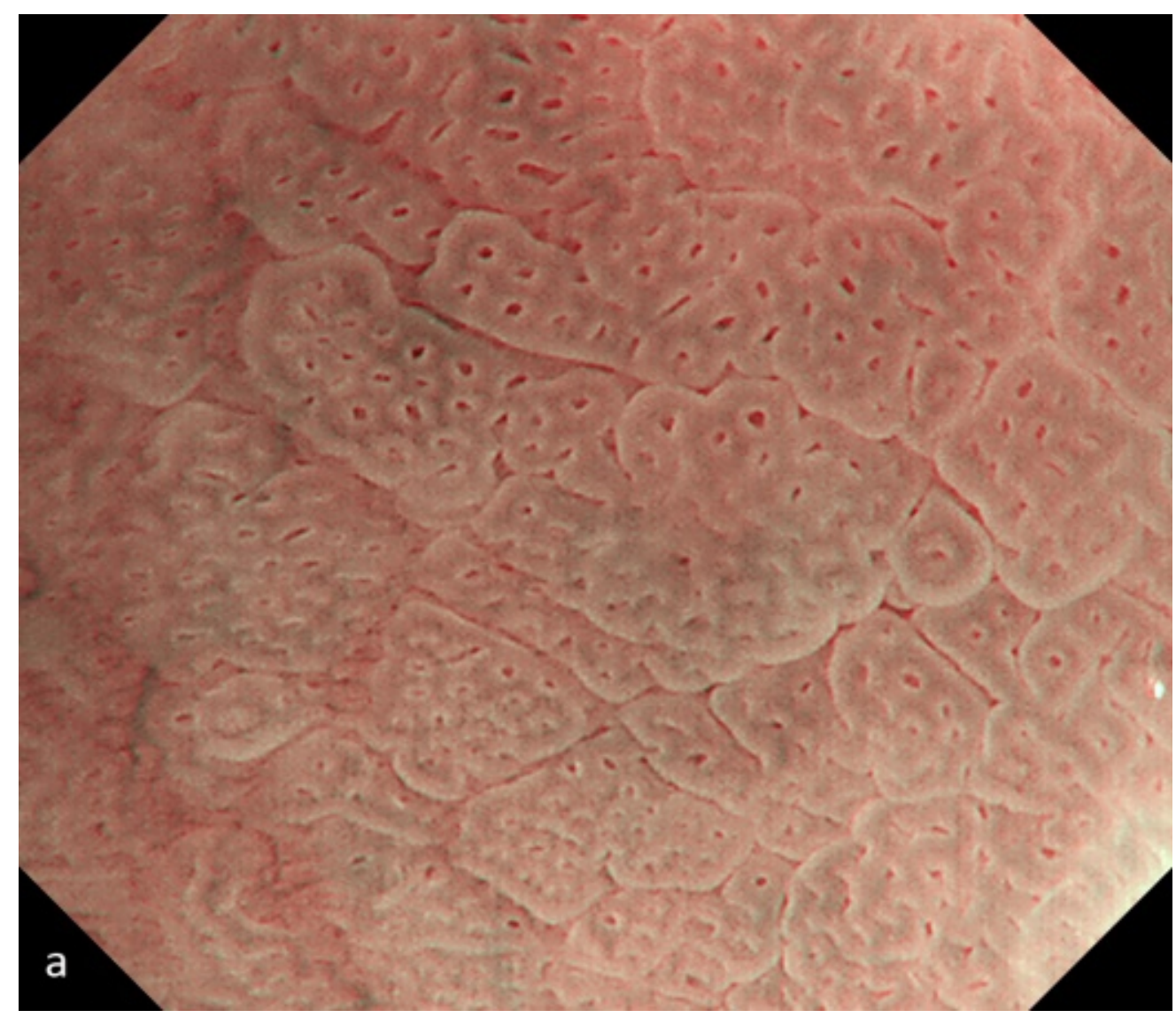

Type I (a) normal gastric body microvasculature = a honeycomb type subepithelial capillary network (SECN) and collecting venules in a regular arrangement.

$60 \times 52 \mathrm{~mm}(220 \times 220$ DPI $)$ 


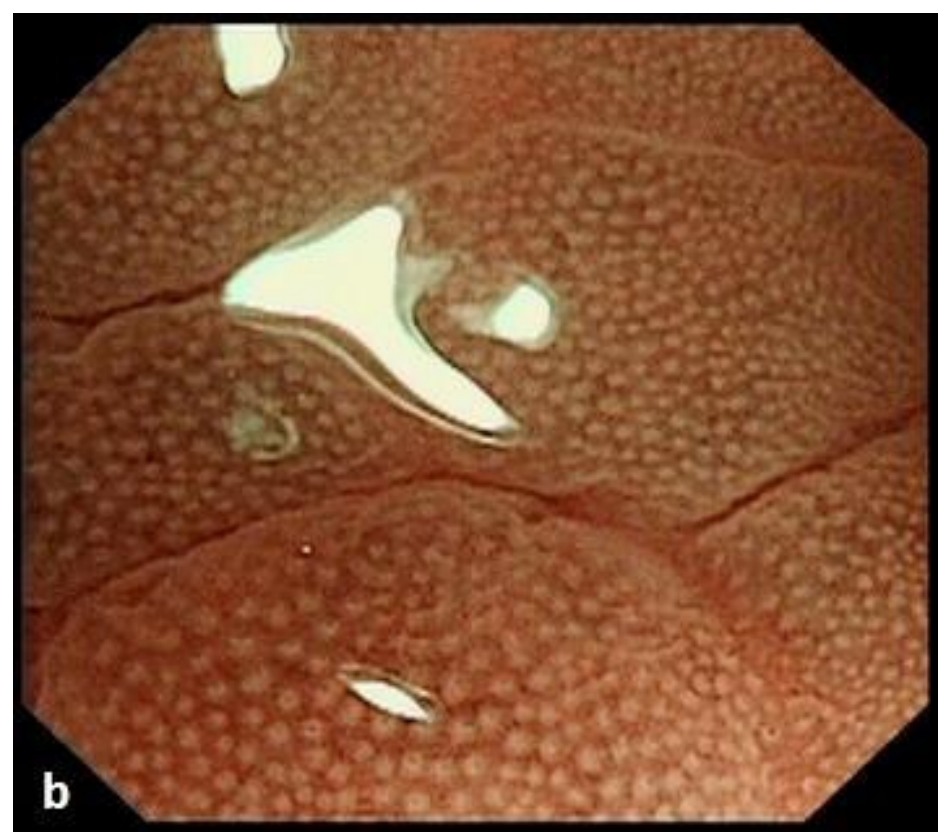

Type II (b) = honeycomb-type SECN with regular round pits, either with or without sulci, but with loss of collecting venules.

$93 \times 83 \mathrm{~mm}(96 \times 96 \mathrm{DPI})$ 


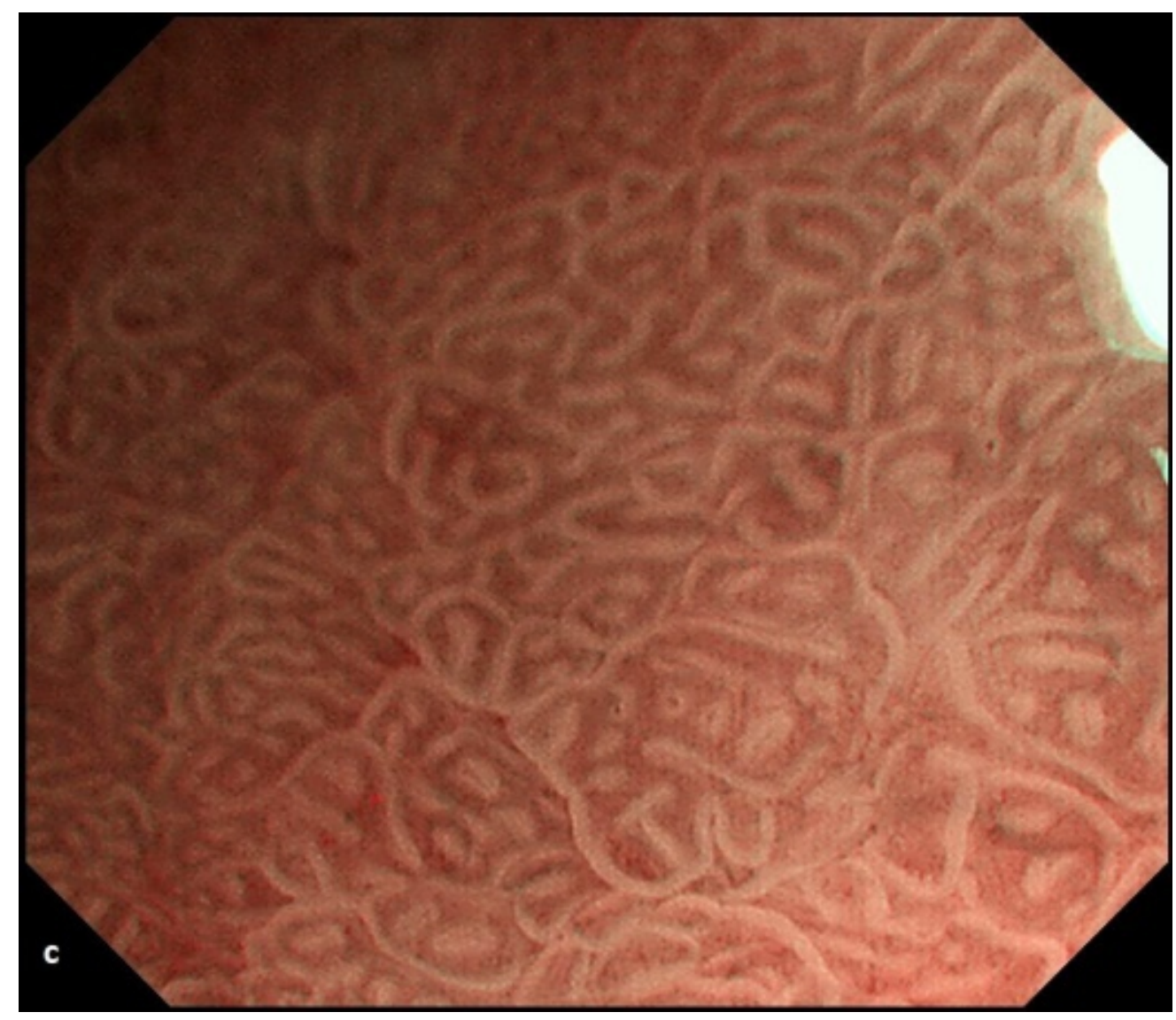

Type III (c) = loss of the normal SECN and collecting venules, with enlarged white pits surrounded by erythema.

$59 \times 51 \mathrm{~mm}(220 \times 220 \mathrm{DPI})$ 


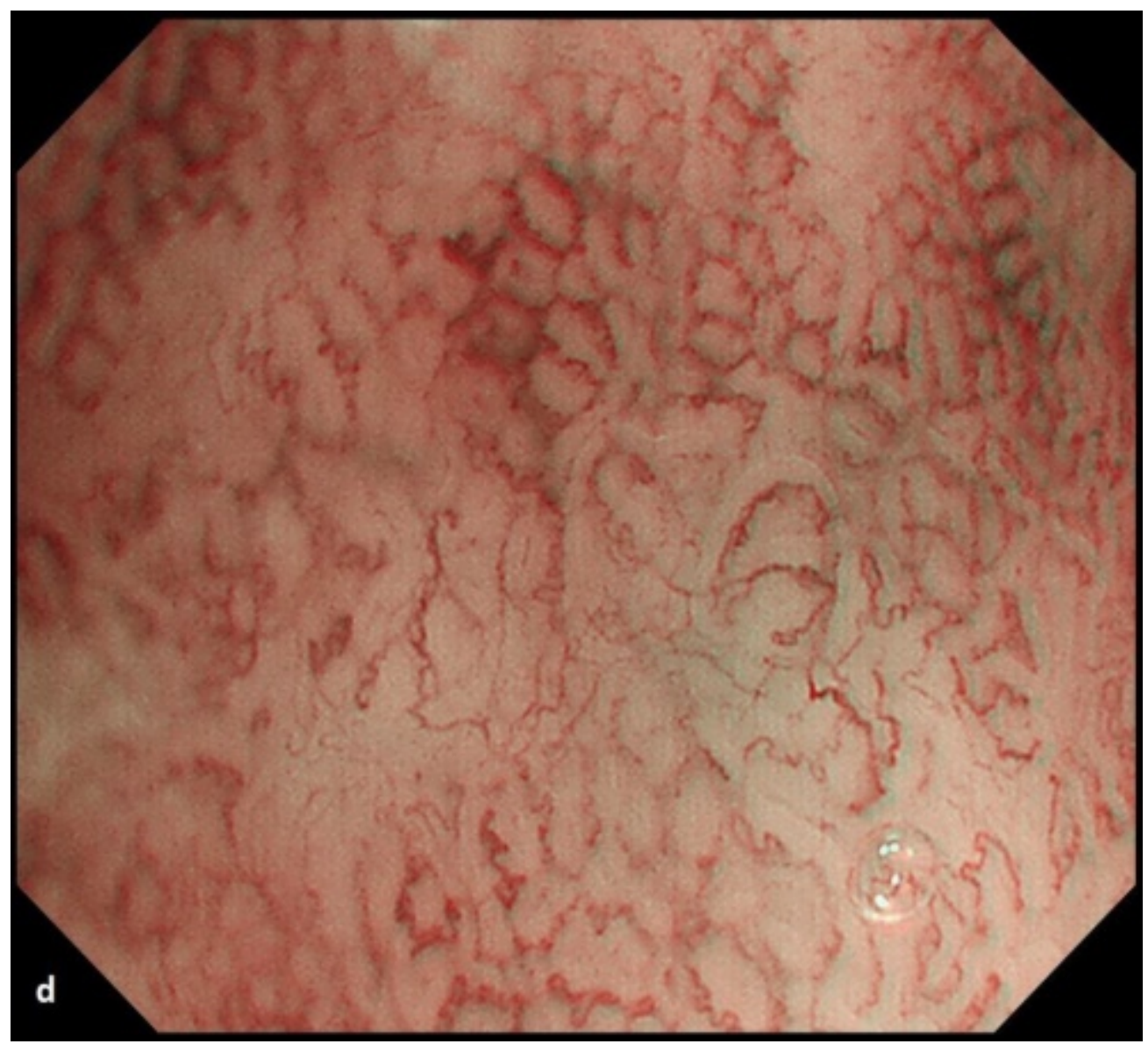

Type IV $(\mathrm{d})=$ loss of the normal SECN and round pits, with irregular arrangement of the collecting venules (18).

$57 \times 52 \mathrm{~mm}(220 \times 220$ DPI $)$ 


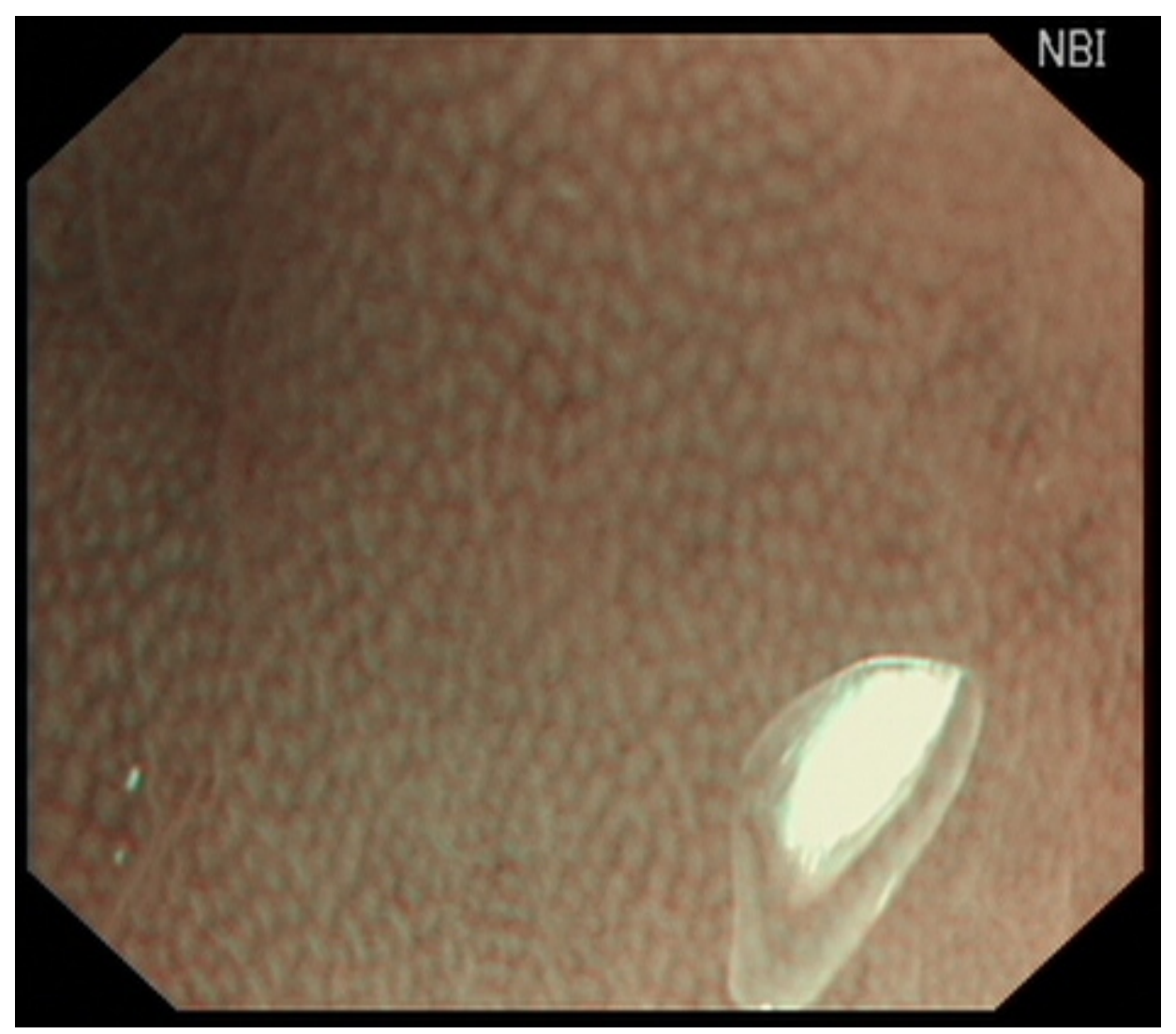

Normal corpus $(A b)$ in image $(A)$ $165 \times 146 \mathrm{~mm}(72 \times 72 \mathrm{DPI})$ 


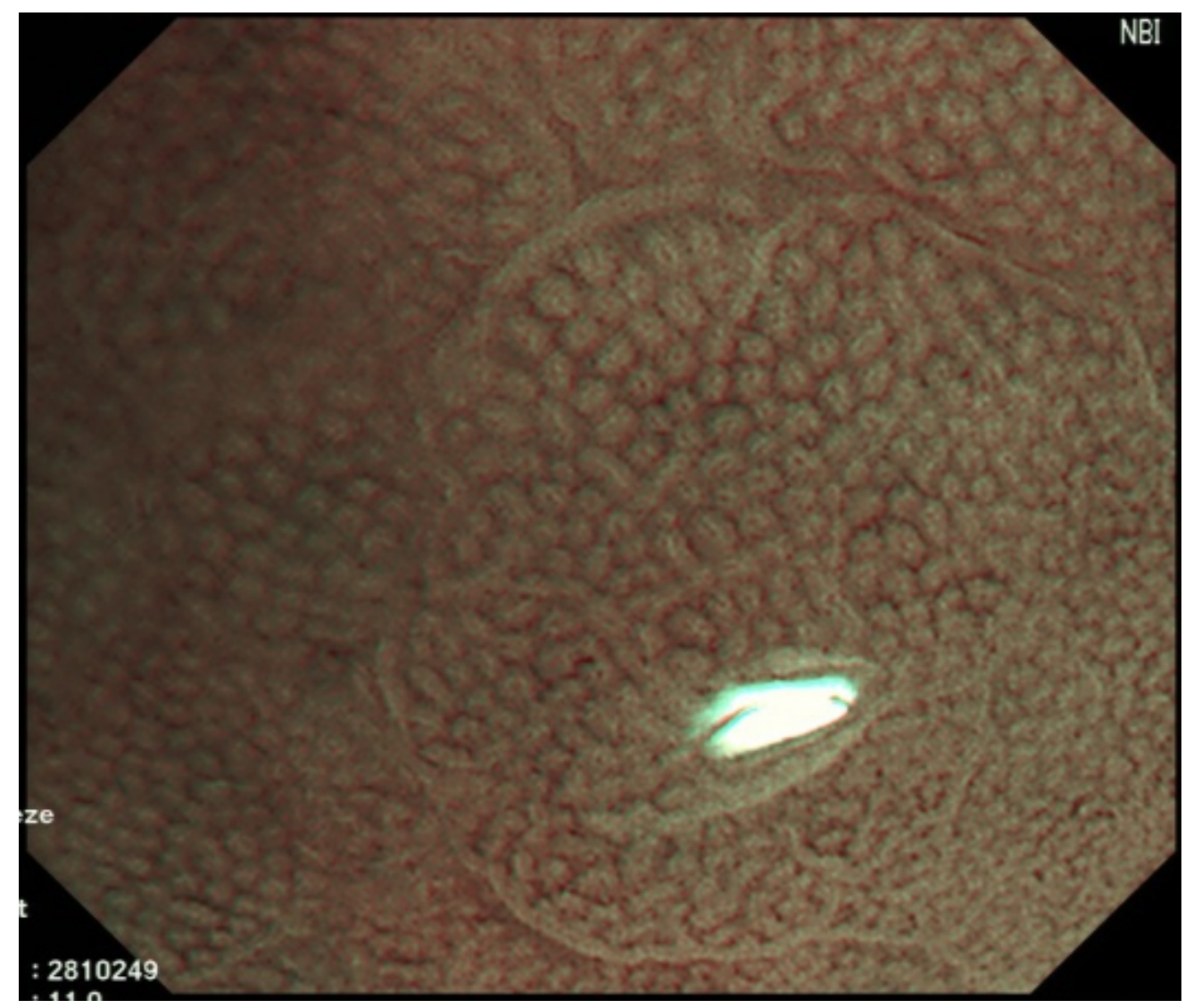

(B) H. pylori gastritis corpus $(A b+)$ $61 \times 51 \mathrm{~mm}(220 \times 220$ DPI $)$ 


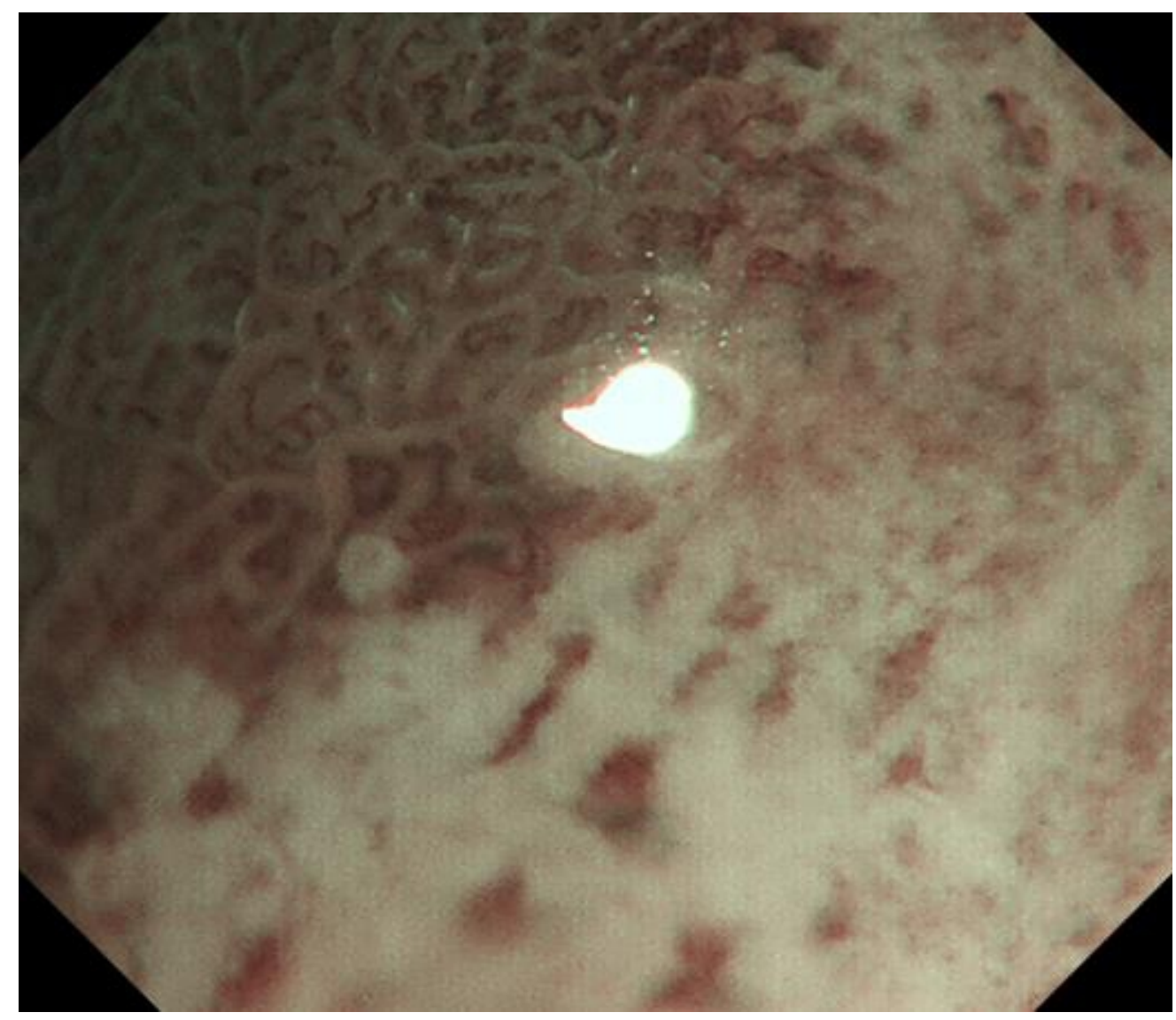

Intestinal metaplasia in corpus with some light blue crest (Bb) in image (C) $59 \times 51 \mathrm{~mm}(220 \times 220$ DPI $)$ 


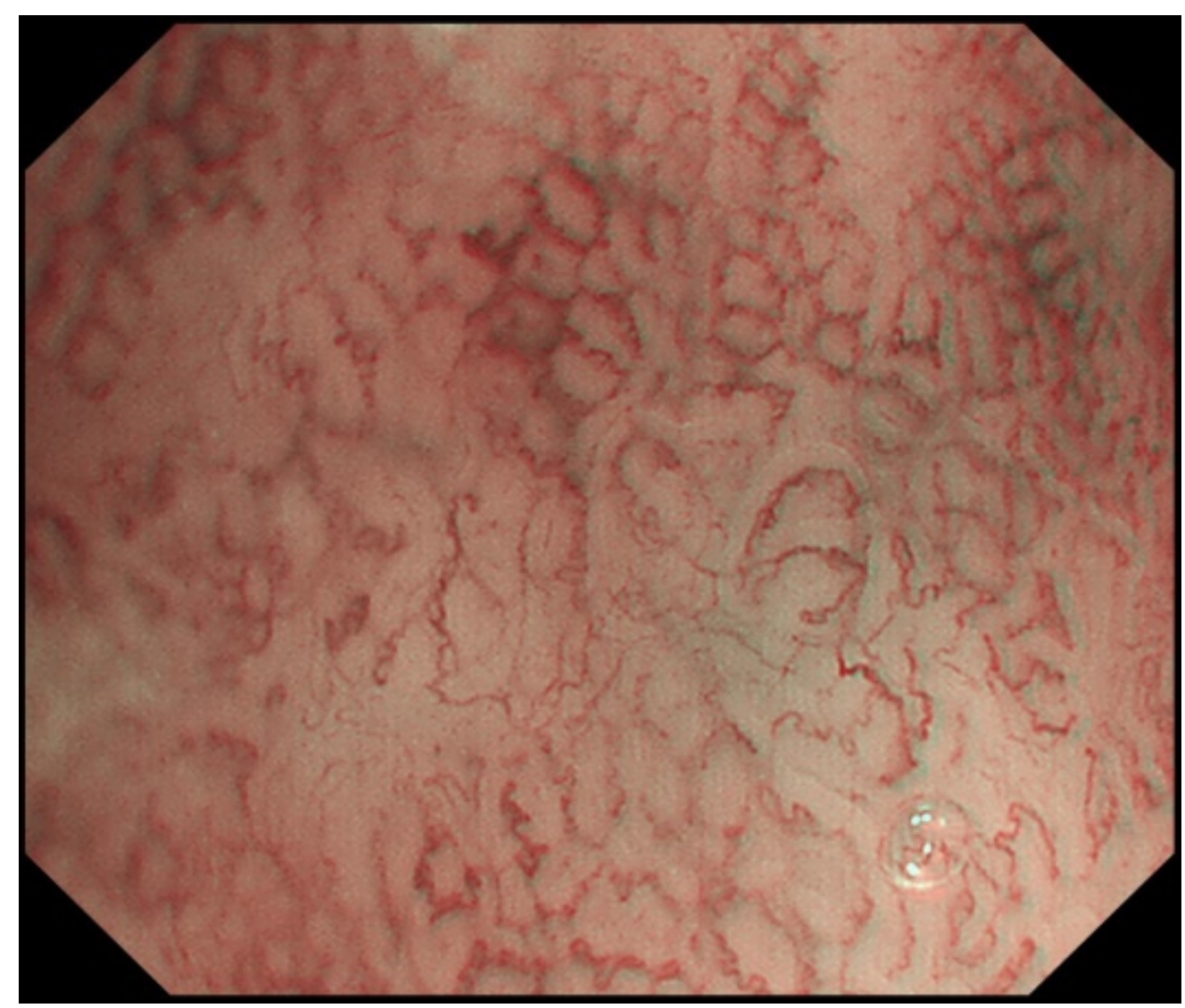

Atrophy in corpus (Db) in image (D). Magnification 115X.

$61 \times 51 \mathrm{~mm}(220 \times 220 \mathrm{DPI})$ 